Gut, 1979, 20, 987-991

\title{
Zymogram studies of human intestinal brush border and cytoplasmic peptidases
}

\author{
Y. S. KIM ${ }^{1}$, Y. W. KIM, H. D. GAINES, AND M. H. SLEISENGER \\ From the Gastrointestinal Research Laboratory, Veterans Administration Hospital, San Francisco, \\ California, and the Department of Medicine, University of California School of Medicine, San Francisco, \\ California, USA
}

SUMMARY Zymogram studies of peptide hydrolases from the human intestinal brush border and cytoplasmic fractions produced multiple bands-that is, up to seven-while the brush border membrane produced only a single band of enzyme activity. With all of the substrates tested except L-leucyl-L-leucyl-L-leucine, a band having anodic mobility identical with that produced by the brush border enzymes was produced by the cytoplasmic enzymes. With L-trileucine as a substrate, no overlapping band was produced. This band in the cytoplasmic fraction was heat sensitive, while that in the brush border fraction was not. Thus it would appear that there is a single human intestinal brush border peptide hydrolase capable of hydrolysing a variety of di- and tri-peptides. This zymogram data together with other previously reported biochemical data strongly indicate that the peptide hydrolases of the brush border and the cytoplasmic fraction of human intestine are distinct.

Peptide hydrolases in the intestinal mucosal cells of man, rat and the guinea-pig have been reported to be localised in two subcellular locations, the brush border and the cytoplasm (Peters, 1970; Heizer et al., 1972; Kimet al., 1972; Kimet al., 1974a, b; Nicholson and Peters, 1978). Studies on the substrate specificities and the physiochemical properties of these two groups of enzymes indicate that they are distinct (Peters, 1970; Heizer et al., 1972; Kim et al., 1972, 1974). Although their precise function has not been firmly established, they are thought to be important in the final stage of digestion of dietary peptides at the mucosal cell surface and within the cytoplasm respectively (Peters, 1970; Kim et al., 1972, 1974a; Matthews, 1975).

Zymogram and biochemical studies of these enzymes in the rat and guinea-pig indicate that these two groups exist in multiple forms (Kim et al., 1972; Donlon and Fottrell, 1972; Fottrell et al., 1972; Schiller et al., 1977; Kim and Brophy, 1976). The electrophoretic mobilities of peptide hydrolases from the brush border and cytoplasmic fraction have been reported to be distinct in the rat intestine (Kim et al., 1972). Other investigators, however, using a similar zymogram method did not observe electrophoretically distinct brush border enzymes in the rat and

\footnotetext{
${ }^{1}$ Address for correspondence: Y. S. Kim, MD (151-M2), Veterans Administration Hospital, 4150 Clement Street, San Francisco, California, USA 94121.

Received for publication 6 June 1979
}

guinea-pig (Donlon and Fottrell, 1972). Studies on the cytoplasmic fraction using a limited number of peptide substrates have indicated that multiple forms of peptide hydrolases also exist in man (Heizer et al., 1972; Kim, 1976; Dolly and Fottrell, 1969). However, more comprehensive studies similar to those in animals have not been carried out in human mucosa.

The present study was carried out (1) to compare zymogram patterns of brush border and cytoplasmic fraction of human intestinal peptide hydrolases using 20 peptides as substrates, and (2) to find a substrate that can distinguish these two groups electrophoretically so that this substrate can be used in the purification of these enzymes from human intestinal mucosa.

\section{Methods}

Ten mucosal biopsy specimens and three surgical specimens all freshly obtained were used for this study. The brush border fraction was prepared from the mucosal scrapings (Schmitz et al., 1973). and the cytoplasmic fraction obtained by homogenising the mucosal scraping in $15 \%$ glycerol and centrifuging the homogenate at $100000 \times g$ for one hour at $4^{\circ} \mathrm{C}$. As a control, the cytoplasmic fraction was also obtained by homogenising the mucosal scrapings in Tris-mannitol buffer, followed by $\mathrm{Ca}^{++}$treatment and $100000 \times g$ centrifugation for one hour at $4^{\circ} \mathrm{C}$. The brush border membrane was purified 22- and 24-fold respectively with regard to trehalase and L-leucyl B-naphthylamidase activities. Trehalase 
activity was determined by the method of Dahlqvist (Dahlqvist, 1964) and peptide hydrolase activity was assayed by the method previously reported from this laboratory (Nicholson and Kim, 1975). The enzymes were solubilised from the brush border membrane by papain digestion and then centrifuged at 100000 $\times g$ for one hour at $4^{\circ} \mathrm{C}$. Zymogram studies were carried out as described previously (Kim et al., 1972).

\section{Results}

As shown in Fig. 1, when L-leucyl-L-leucine or L-leucyl-L-leucyl-L-leucine was used as substrate, a single band with anodic mobility was observed with solubilised brush border membrane peptidases. This band was somewhat polydisperse. Peptidases associted with the brush border membranes remained at the origin without papain treatment. with those given by the same fraction prepared in glycerol.

Figure 2 illustrates diagrammatically the representative results of a series of zymograms from cytoplasmic and brush border fractions of human small intestine using 15 dipeptides and five tripeptides as substrates. The cytoplasmic fraction of human jejunal mucosa yielded zymogram patterns which could be broadly classified into seven different types. Dipeptides such as L-phenylalanyl-L-leucine, L-methionyl-L-leucine and L-phenylalanyl-L- tryosine and L-leucyl-L-alanine gave patterns similar to those shown by L-leucyl-L-leucine. Dipeptides such as glycyl-L-leucine, L-valyl-L-leucine, and L-prolylL-phenylalanine gave patterns similar to those shown by L-prolyl-L-leucine. There were four fast migrating bands produced when L-leucylproline was the substrate; these were also seen with L-leucyl-glycine,

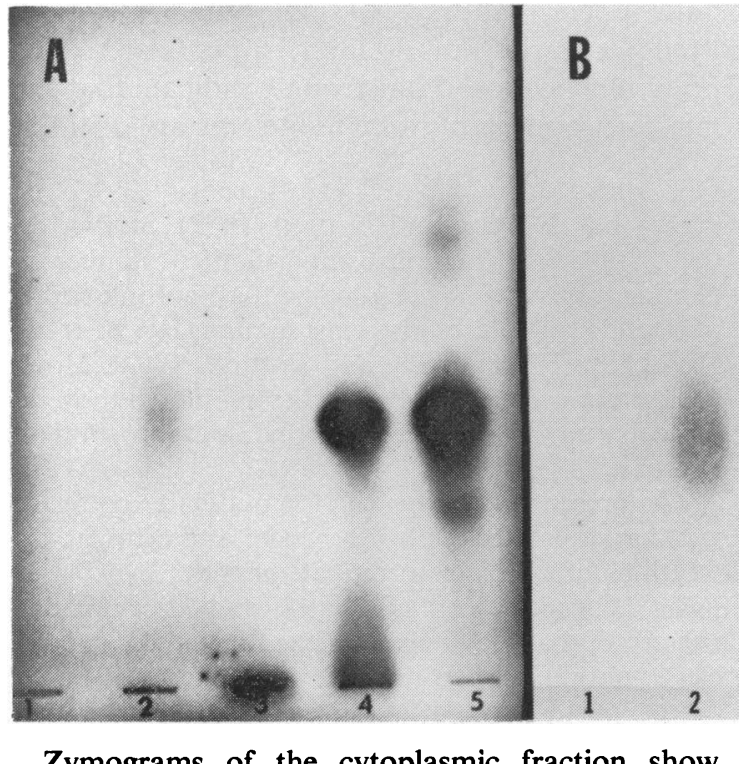

Zymograms of the cytoplasmic fraction show multiple zones of enzyme activity with anodic mobility. The most prominent band was in the intermediate zone; it had similar electrophoretic mobility to that of the brush border membrane when L-leucylL-leucine was the substrate. Papain treatment of the cytoplasmic fractions abolished the activities of the fast and slow moving bands, but reduced the activity of the intermediate major band only moderately with L-leucyl-L-leucine as a substrate, while the treatment completely inactivated the enzyme activity when L-leucyl-L-leucyl-L-leucine was used. Although longer incubation time was necessary for the adequate development of zymograms due to reduced enzyme activity, the cytoplasmic fraction prepared in Trismannitol buffer gave zymogram patterns identical
Fig. 1 Representative zymogram of human intestinal peptide hydrolases using L-leucyl-Lleucine $(A)$ and L-leucyl-L-leucylL-leucine $(B)$ as substrates. The samples applied were: (1) papain alone, (2) papain treated brush border fraction, (3) untreated brush border fraction, (4) papain treated cytoplasmic fraction, and (5) untreated cytoplasmic fraction.

which showed two additional bands with electrophoretic mobilities similar to the slowest moving bands of L-prolyl-L-leucine. The cytoplasmic fraction also showed weak activity against L-leucyl-Bnaphthylamide and L-leucinamide.

The solubilised brush border membrane peptide hydrolases gave a single band with the same electrophoretic mobility regardless of the substrate used. The anodic mobility of the brush border membrane enzyme was similar to that of the major band of intermediate electrophoretic mobility produced by the cytoplasmic enzymes. A trace activity could be detected consistently when prolyl-L-leucyl-proline was the substrate. Figure 3 shows the zymogram pattern produced by the brush border and cytoplasmic enzymes when L-leucyl-L-leucine and 


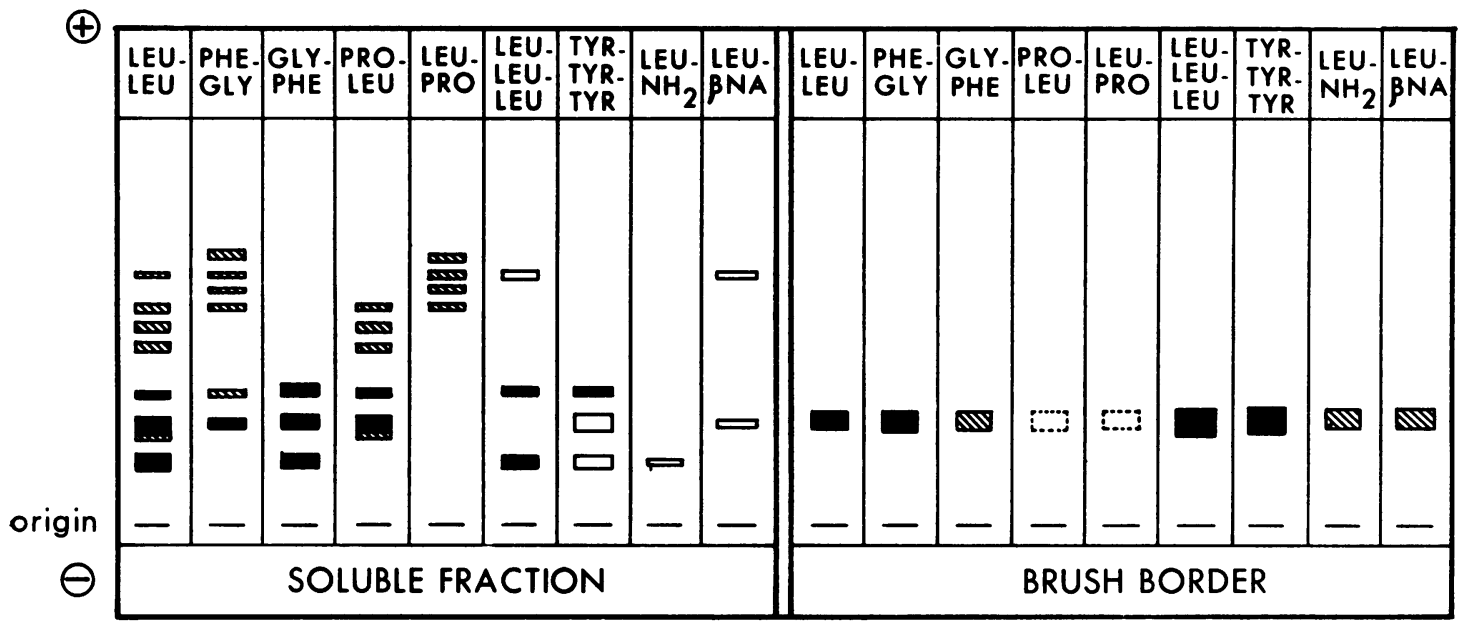

Fig 2 Schematic diagram of representative zymograms of cytoplasmic and brush border peptidases using different subs-

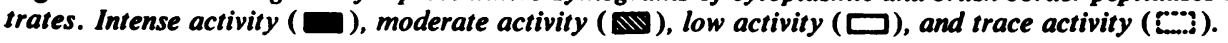

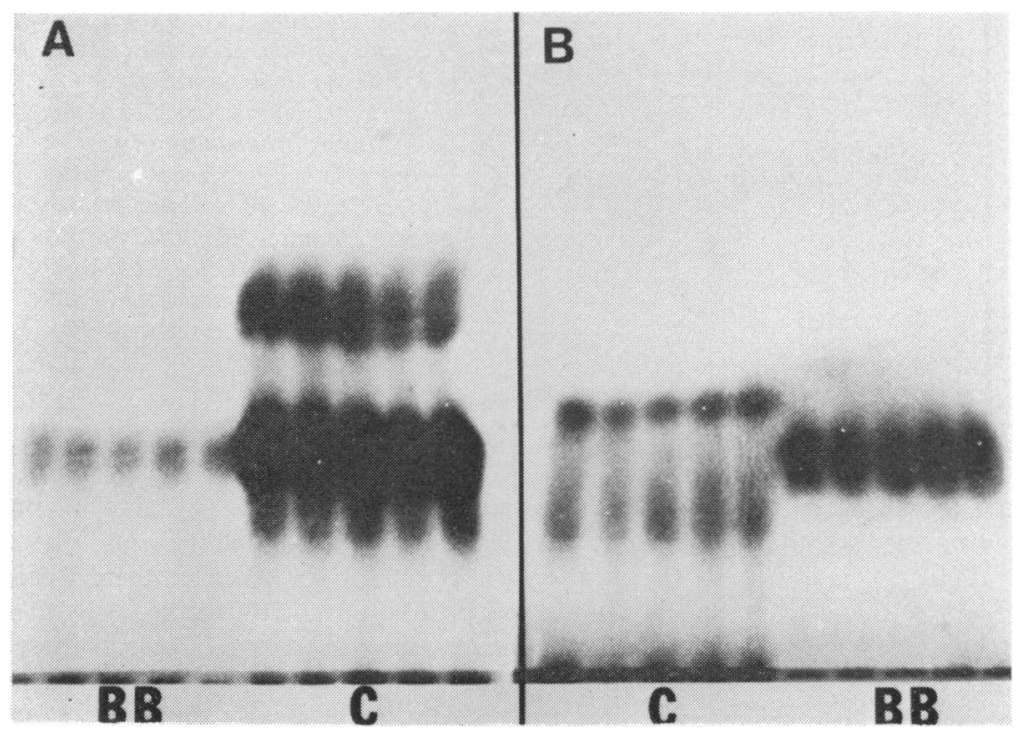

Fig. 3 Zymogram pattern using L-leucyl-L-leucine $(A)$ and L-leucyl-L-leucyl-L-leucine $(B)$ as substrates for brush border (BB) and cytoplasmic peptidases $(C)$.
L-leucyl-L-leucyl-L-leucine were the substrates. The brush border enzymes gave a band with electrophoretic mobility indistinguishable from that produced by the cytoplasmic enzymes when L-leucyl-Lleucine was the substrate. In contrast, when L-leucylL-leucyl-L-leucine was used as a substrate, cytoplasmic enzymes failed to produce a band with electrophoretic mobility similar to that produced by the brush border membrane peptidases.

Differential effects of heat treatment on the activities of peptide hydrolases of the brush border and cytoplasmic fractions are shown in Fig. 4. The brush border membrane peptidases were more stable than the cytoplasmic enzymes. After 20 minutes of heat treatment at $60^{\circ} \mathrm{C}$, over $60 \%$ of the brush border enzyme activity still remained, while the cytoplasmic enzyme activity was completely abolished. The effect of heat treatment on the activities of different iseoenzyme bands of peptide hydrolases of the brush border and cytoplasmic fractions is shown in Fig. 5. The band of activity produced by the solubilised brush border membrane showed considerable resistance to heat treatment and remained as a single band even after prolonged heat treatment. All the isoenzyme bands of the cytoplasmic fraction showed a similar pattern of heat inactivation and at 


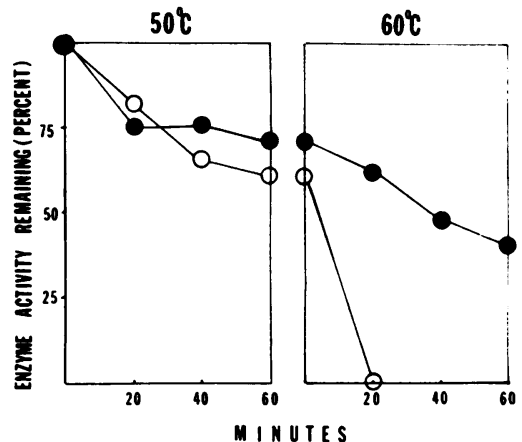

Fig. 4 The effect of heat treatment on the activities of cytoplasmic (o) and brush border (0) peptidases when L-leucyl-L-leucine was the substrate. starch gel (Kim et al., 1972) and polyacrylamide gel electrophoresis (Kim and Brophy, 1976).

However, Fottrell and his associates observed that the zymogram produced by the cytoplasmic peptide hydrolases obtained from both rat and guinea-pig intestine contained a band with electrophoretic mobility identical with that produced by the brush border enzymes (Donlon and Fottrell, 1972; Fottrell et al., 1972). Using two dipeptides as substrate they observed only a single band with the brush border of rat and guinea-pig intestine (Fottrell et al., 1972). Furthermore, they noted that the activity of guinea-pig cytoplasmic enzymes failed to be inhibited completely by $10^{-4} \mathrm{M}$ p-choromercuribenzoate (Fottrell et al., 1972), unlike that of the cytoplasmic enzymes of the rat intestine, the activity

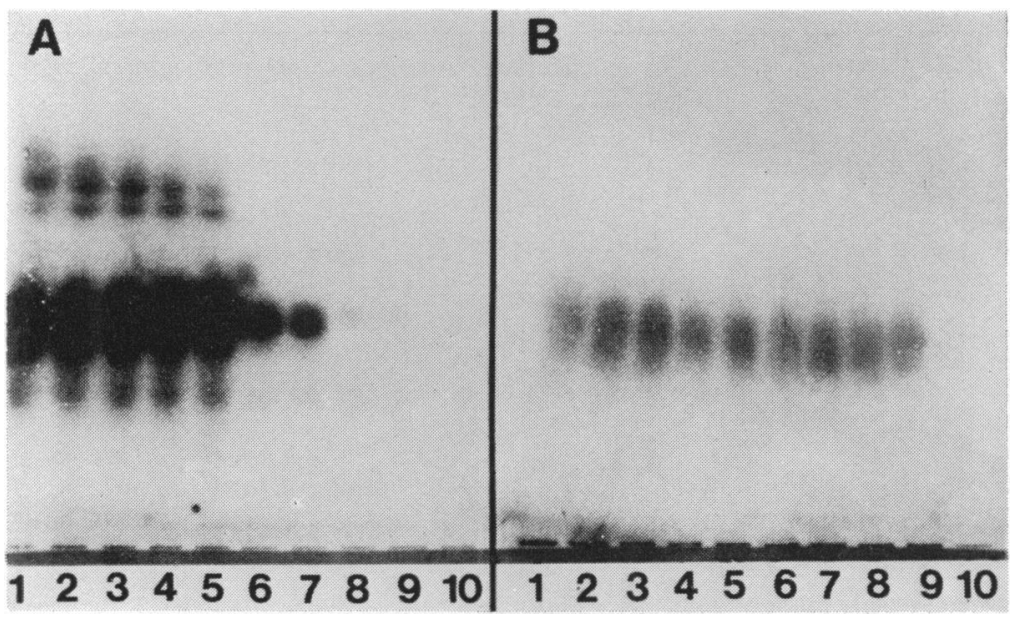

Fig. 5 The effect of heat treatment on the zymogram patterns of cytoplasmic (A) and brush border peptidase activities (B) when L-leucyl-L-leucine was the substrate. Numbers indicate the conditions of incubation: (1) control, (2) $37^{\circ} \mathrm{C}$ for 30 minutes, (3) $37^{\circ} \mathrm{C}$ for 60 minutes, (4) $40^{\circ} \mathrm{C}$ for 10 minutes, (5) $40^{\circ} \mathrm{C}$ for 30 minutes, (6) $40^{\circ} \mathrm{C}$ for 60 minutes, (7) $50^{\circ} \mathrm{C}$ for 30 minutes, (8) $60^{\circ} \mathrm{C}$ for 30 minutes, (9) $60^{\circ} \mathrm{C}$ for 60 minutes, (10) $70^{\circ} \mathrm{C}$ for 10 minutes.

higher temperature the remaining enzyme activity consisted solely of the major band with intermediate mobility.

\section{Discussion}

It has previously been reported that peptide hydrolases of the intestinal mucosal cells exist in mutiplemolecular forms (Dolly and Fottrell, 1969; Dolly et al., 1971; Kim et al., 1972; Donlon and Fottrell, 1972; Fottrell et al., 1972). In the rat, zymogram studies indicated that up to nine molecular forms of peptide hydrolases may exist within the cytoplasm and two major forms within the brush border (Kim et al., 1972).

Recent isolation and characterisation of different molecular forms of the enzymes from the rat intestinal mucosa have substantiated these observations (Kim et al., 1972; Schmitz et al., 1973; Kim and Brophy, 1976). Furthermore, in the rat, these two enzyme groups do not give overlapping bands but have distinct electrophoretic mobilities on both of which was completely abolished by this agent (Heizer et al., 1972). From these observations, these workers raised the possibility of whether there were species differences or differential contributions by the adsorbed pancreatic enzymes to account for these observed differences.

The present study indicates clearly that there is at least one molecular form of the peptide hydrolase capable of hydrolysing a variety of di- and tripeptides in the human intestinal brush border, whereas there are two such molecular forms of the enzyme in rat intestine (Kim et al., 1972; Kim and Brophy, 1976). It indicates further that, within human intestine, unlike that in the rat, there is a band produced by the cytoplasmic enzymes, the electrophoretic mobility of which overlaps that of the brush border enzymes (Kim et al., 1972; Kim and Brophy, 1976). The polydisperse nature of the brush border membrane enzyme band may in part be due to the microheterogeneity in oligosaccharide side-chains of this glycoprotein enzyme. 
Recent quantitative analytical subcellular fractionation studies (Nicholson and Peters, 1978) demonstrated the presence of a substantial amount of tri-leucine hydrolysing activity but the total absence of di-leucine hydrolysing activity in human intestinal brush borders. Our studies indicate the presence of peptide hydrolase activity against both peptides in the human intestinal brush borders. Although our studies are primarily qualitative, demonstration of a distinctly different heat stability property of peptide hydrolases from two subcellular fractions when dileucine is used as a substrate suggests that the enzyme activity for the dipeptide is likely to be present in the human intestinal brush border. The reasons for these apparently different results are not clear at the present time. Additional studies are necessary to elucidate the substrate specificity and the kinetic property of the human brush border membrane peptide hydrolase.

The conclusion that the band produced by the brush border membrane is distinct from that produced by the cytoplasmic enzymes in man can be drawn from the following observations: first, when tri-leucine was the substrate, no band overlapping with the cytoplasmic enzymes was produced. Lleucyl-L-leucyl-L-leucine will thus be a very useful substrate when determining the cross-contamination with cytoplasmic enzymes during the course of purification of human intestinal brush border peptide hydrolase; second, the heat inactivation studies showed a marked difference in the heat resistance of the respective bands produced by the two subcellular fractions.

The previously reported biochemical findings that the cytoplasmic enzymes of human small intestinal mucosa are capable of hydrolysing di- or tri-peptides but not higher length peptides, whereas the brush border enzymes can readily hydrolyse these longer molecules (Kim et al., 1974a; Kim and Brophy, 1976; Nicholson and Peters, 1978) are consistent with our conclusion that the peptide hydrolases of human intestinal brush border are distinct from cytoplasmic enzymes.

This investigation was supported by Grant AM 17938 from the United States Public Health Service.

\section{References}

Dahlqvist, A. (1964). Method for assay of intestinal disaccharidases. Analytical Biochemistry, 7, 18-25.

Dolly, J. O., Dillon, A., Duffy, M. J., and Fottrell, P. F. (1971). Further studies on multiple forms of peptidases in mammalian tissues including intestinal mucosa from children with treated and untreated coeliac disease. Clinica Chimica Acta, 31, 55-62.

Dolly, J. O., and Fottrell, P. F. (1969). Multiple forms of dipeptidases in normal human intestinal mucosa and in mucosa from children with coeliac disease. Clinica Chimica Acta, 26, 555-558.

Donlon, J., and Fottrell, P. F. (1972). Studies on substrate specificities and subcellular location of multiple forms of peptide hydrolases in guinea-pig intestinal mucosa. Comparative Biochemistry and Physiology, 41B, 181193.

Fottrell, P. F., Keane, R., and Harley, J. (1972). Comparison of peptide hydrolases from brush border and cytosol fractions of rat and guinea-pig intestinal mucosa. Comparative Biochemistry and Physiology, 43B, 129-135.

Heizer, W. D., Kerley, R. L., and Isselbacher, K. J. (1972). Intestinal peptide hydrolases differences between brush border and cytoplasmic enzymes. Biochimica et Biophysica Acta, 264, 450-461.

Kim, Y. S., Birtwhistle, W., and Kim, Y. W. (1972). Peptide hydrolases in the brush border and soluble fractions of small intestinal mucosa of rat and man. Journal of Clinical Investigation, 51, 1419-1430.

Kim, Y. S., and Brophy, E. J. (1976). Rat intestinal brush border membrane peptidases. 1. Solubilization, purification, and physicochemical properties of two different forms of the enzyme. Journal of Biological Chemistry, 251, 3199-3205.

Kim, Y. S., Kim, Y. W., and Sleisenger, M. H. (1974a). Studies on the properties of peptide hydrolases in the brush border and soluble fractions of small intestinal mucosa of rat and man. Biochimica et Biophysica Acta, 370, 283-296.

Kim, Y. S., Nicholson, J. A., and Curtis, K. J. (1974b). Intestinal peptide hydrolases: peptide and amino acid absorption. Medical Clinics of North America, 58, 1397-1411.

Matthews, D. M. (1975). Intestinal absorption of peptides. Physiological Review, 55, 537-608.

Nicholson, J. A., and Kim Y. S. (1975). A one-step L-amino acid oxidase assay for intestinal peptide hydrolase activity. Analytical Biochemistry, 63, 110-117.

Nicholson, J. A., and Peters, T. J. (1978). Subcellular distribution of hydrolase activities for glycine and leucine homopeptides in human jejunum. Clinical Science and Molecular Medicine, 54, 205-207.

Peters, T. J. (1970). Intestinal peptidases. Gut, 11, 720-725.

Peters, T. J. (1970). The subcellular localization of di- and tri-peptide hydrolase activity in guinea-pig small intestine. Biochemical Journal, 120, 195-203.

Schiller, C. M., Huang, T. I., and Heizer, W. D. (1977). Isolation and characterization of four peptide hydrolases from the cytosol of rat intestinal mucosa. Gastroenterology, 72, 93-100.

Schmitz, J., Preiser, H., Maestracci, D., Ghosh, B. K., Cerda, J., and Crane, R. K. (1973). Purification of the human intestinal brush border membrane. Biochimica et Biophysica Acta, 323, 98-112. 